\title{
Interface design of environmentally friendly carbon nanotube-filled polyester composites: Fabrication, characterisation, functionality and application
}

\author{
C. S. Wu*, H. T. Liao \\ Department of Applied Cosmetology, Kao Yuan University, Kaohsiung County, Taiwan, Republic of China
}

Received 16 August 2016; accepted in revised form 28 October 2016

\begin{abstract}
Polyhydroxyalkanoate (PHA) composites containing multi-walled carbon nanotubes (MWCNTs) were prepared using a process of melt-blending three-dimensional (3D) printing filaments. Maleic anhydride (MA)-grafted polyhydroxyalkanoate (PHA-g-MA) and chemically modified MWCNTs (MWCNTs-COOH) were used to improve the compatibility and dispersibility of the MWCNTs within the PHA matrix. Structural, morphological, thermal and mechanical characterisations revealed dramatic enhancements in the thermal and mechanical properties of the PHA- $g$-MA/MWCNTs-COOH composites compared with PHA, because of the formation of ester carbonyl groups through the reaction between MA groups of PHA- $g$-MA and the carboxylic acid groups of the MWCNTs-COOH. For example, with an addition of $1.0 \mathrm{wt} \%$ of MWCNTs$\mathrm{COOH}$, the initial decomposition temperature and tensile strength at failure increased by $72{ }^{\circ} \mathrm{C}$ and $16.0 \mathrm{MPa}$, respectively. Moreover, MWCNTs or MWCNTs-COOH enhanced the antibacterial activity and static dissipative properties of the composites. Composites of PHA-g-MA or PHA containing MWCNTs or MWCNTs-COOH had better antibacterial activities and antistatic properties.
\end{abstract}

Keywords: processing technologies, antibacterial activity, antistatic properties, multi-walled carbon nanotubes, three-dimensional reinforcement

\section{Introduction}

In 1991, S. Iijima of Japan NEC discovered carbon nanotubes. These are conducting non-metallic materials composed entirely of carbon atoms [1]. The source of their electrical conductivity, which lies between that of metals and semiconductors, is various $\pi-\pi$ conjugate structures [2,3]. Additionally, carbon nanotubes are characterised by their small particle size, large specific surface area, low density, thermal stability and good mechanical properties [4-6]. They are frequently used in hydrogen storage applications (as double-layer capacitance pole materials), as well as in field emission displays and as conducting and antistatic composites [7-10]. They are also used in organic polymer composites, where they are becoming increasingly noticed by industry. The inorganic carbon nanotubes remedy several deficiencies of polymers, e.g. generally poor thermal stabilities, mechanical strengths and electrical conductivities [11-13]. The environmentally friendly polymers conform to the international trend of energy savings and carbon reduction and are free of environmental hazards; they include polylactic acid (PLA), polyhydroxyalkanoates (PHA) and polycaprolactone (PCL) $[14,15]$. PHA, which is a bio-based material polymerised by microorganisms, has good ductility, processing, high filler acceptance and good mechanical properties; thus, it is one of the most promising environmentally friendly aliphatic polyester materials $[16,17]$. To enhance the compatibility of aliphatic polymers and

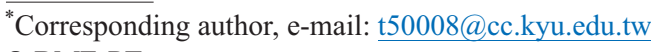
(C) BME-PT 
carbon nanotubes in composites, similar methods of improvement of aliphatic polyesters properties (e.g. PLAs) by modification with carbon nanotubes have been studied $[18,19]$. The previous researches has used acid-etched carbon nanotubes to increase the number of $-\mathrm{COOH}$ groups on the surface side chains, thus increasing the polar groups on the carbon nanotube surface. For example, Chen et al. [20] used a mixture of concentrated sulfuric and hydrochloric acids, Xiong et al. [21] used recycled concentrated sulfuric and nitric acids, and Bajada et al. [22] used concentrated hydrochloric acid with ultrasonic treatment.

In the 1980s, the three-dimensional (3D) printing technologies have been gradually used in the field of rapid prototyping to accelerate commercial product research and development. Recently, the 3D printing has been identified as a key aspect of a new Industrial Revolution [23, 24]. Fused deposition modeling (FDM) is the most widely used process for 3D printing filaments; such as nylon, acrylonitrile butadiene styrene (ABS), polystyrene (PS) and PLA polymers $[25,26]$. However, most FDM filament materials are not environmentally friendly because thermofusion printing can release toxic substances [27]. In this work, acid-treated multi-walled carbon nanotubes (MWCNTs) and maleic anhydride (MA)modified PHA were separately prepared and then melt blended to improve the functionality and environmental aspects of the composite. The thermal and mechanical properties, antibacterial activity, electrical conductivity and antistatic properties of the composites were evaluated. A functional 3D printing filament was made by extrusion; no toxic substances were released during printing, thereby protecting the local workspace and the environment [28, 29]. For the development of MWCNT-containing polymer nanocomposites for 3D printing, some recent works on electrically conducting 3D printing thermoplastic materials incorporating CNTs had been proposed $[30,31]$. This work furthers the development of PHA-MWCNTs composites.

\section{Experimental}

\subsection{Materials}

Commercial-grade polyhydroxyalkanoate (PHA) (EM 5400F, with a weight average molecular weight $\left(M_{\mathrm{w}}\right)$ of 596000 , a number average molecular weight $\left(M_{\mathrm{n}}\right)$ of 325000 , a polydispersity index of 1.83) was obtained from Shenzhen Ecomann
Biotechnology Co., Ltd. (Shenzhen, China). Multiple-walled carbon nanotubes (MWCNTs, purity $>95 \%$, diameter $=10-40 \mathrm{~nm}$ ), produced via chemical vapour deposition (CVD) were purchased from Shenzhen Nanotech Port Co. (Shenzhen, China). Sulfuric acid (96\%), nitric acid (69.5\%), MA and dicumyl peroxide (DCP) were obtained from the Aldrich Chemical Corporation (Milwaukee, WI, USA). Other reagents were purified using conventional methods.

\subsection{Preparation of the modified MWCNTs, PHA and their composites}

The modification of the MWCNTs and PHA, and the preparation of the composite material, are illustrated in Figure 1. Crude MWCNTs (ca. $500 \mathrm{mg}$ ) were stirred in a concentrated $\mathrm{H}_{2} \mathrm{SO}_{4} / \mathrm{HNO}_{3}$ (1:3) mixture $(30 \mathrm{~mL})$ at $130-140{ }^{\circ} \mathrm{C}$ for $1 \mathrm{~h}$ to oxidatively generate carboxyl functional groups (MWCNTs-COOH) with carboxyl content of $3.66 \mathrm{wt} \%$.

Maleic anhydride-grafted polyhydroxyalkanoate (PHA-g-MA) copolymer was prepared as follows. The PHA was dissolved by stirring at $60 \mathrm{rpm}$ in dichloromethane in a round-bottomed flask under a nitrogen $\left(\mathrm{N}_{2}\right)$ atmosphere at $50 \pm 2{ }^{\circ} \mathrm{C}$. A mixture of $\mathrm{MA}$ and DCP was added, in four equal portions at 2 min intervals, to the PHA solution to allow grafting to take place. Preliminary experiments established that the reaction reached equilibrium in less than $12 \mathrm{~h}$. Thus, reactions were allowed to progress for $12 \mathrm{~h}$. The MA loading of the dichloromethane-soluble polymer was determined by titration and expressed as the grafting percentage [32]. PHA-g-MA had a $M_{\mathrm{w}}$ of 591000 , a $M_{\mathrm{n}}$ of 312700 , a polydispersity index of 1.89 . The grafting percentage was $0.96 \mathrm{wt} \%$. The loadings of DCP and MA were maintained at 0.3 and $10 \mathrm{wt} \%$, respectively.

Composites were prepared using a 'Plastograph' $200 \mathrm{Nm}$ W50EHT mixer with a blade-type rotor (C.W. Brabender Instruments, Inc., Hackensack, NJ, USA). Prior to composite formation, MWCNTs and MWCNTs-COOH samples were dried in a vacuum oven at $70^{\circ} \mathrm{C}$ for 2 days. Composites of PHA/ MWCNTs or PHA-g-MA/MWCNTs-COOH were prepared with $0,0.5,1,2$ and $3 \mathrm{wt} \%$ of inorganic filler. The composite mixture (ca. $40 \mathrm{~g}$ ) was blended at $50 \mathrm{rpm}$ and $130-140^{\circ} \mathrm{C}$ for $15 \mathrm{~min}$ with an $\mathrm{Sb}_{2} \mathrm{O}_{3}$ catalyst (catalyst loading was $0.03 \mathrm{wt} \%$ ). Composite mixtures of PHA-g-MA/MWCNTs-COOH were placed in a vacuum oven at $80^{\circ} \mathrm{C}$ for 1 day for continued esterification. Standard specimens were pre- 


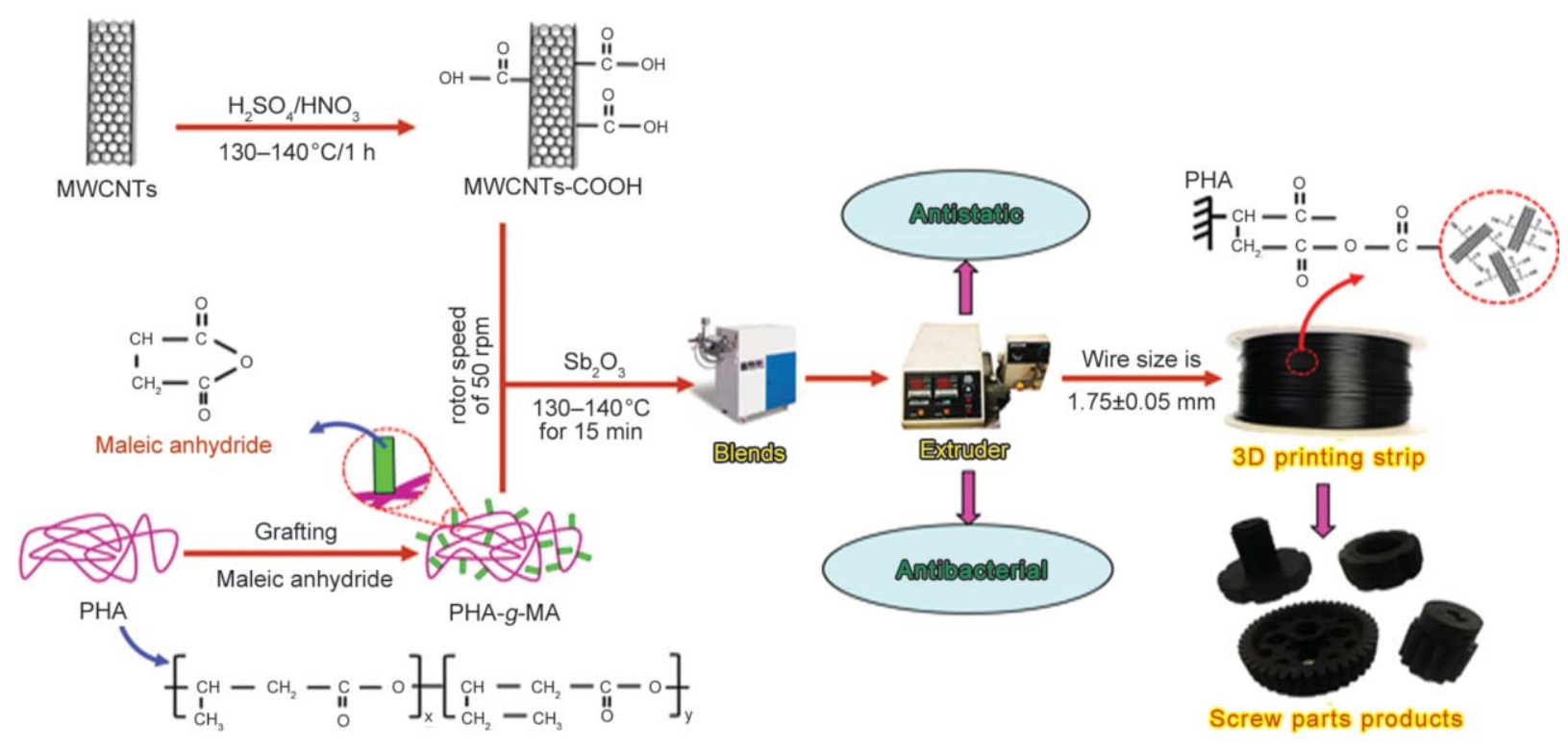

Figure 1. Reaction scheme detailing the modification of multi-walled carbon nanotubes (MWCNTs) and polyhydroxyalkanoate (PHA), and the fabrication of three-dimensional (3D) printing filaments

pared by pressing the hybrid composites into $1 \mathrm{~mm}$ thick plates using a hydraulic press at $140^{\circ} \mathrm{C}$ and $100 \mathrm{~atm}$. After pressing, the plates were placed in a dryer for cooling. Prior to characterisation, the specimens were conditioned for 1 day at a relative humidity of $30 \pm 5 \%$.

\subsection{Fabrication of the 3D printing filaments}

An extruder (Model TUS-194T; Atlas Electric Devices Company, Chicago, IL, USA) was used to make the $3 \mathrm{D}$ printing filaments at a fabrication temperature of $130-140^{\circ} \mathrm{C}$ and a screw rotation rate of $50 \mathrm{rpm}$. A sample (PHA, PHA-g-MA or a composite) was placed in the extruder and heated until molten. The sample was slowly extruded and the extrudate cooled by a cooling system. The coiler speed was used to control the diameter of the $3 \mathrm{D}$ printing filament to $1.75 \pm 0.05 \mathrm{~mm}$. Figure 1 shows the fabrication of the $3 \mathrm{D}$ printing filaments and products from the composite materials [33].

\subsection{Characterisation}

Infrared spectra of the samples were obtained using an FTS-7PC Fourier transform-infrared (FT-IR) spectrophotometer (Bio-Rad, Hercules, CA, USA). The spectra were obtained at $2 \mathrm{~cm}^{-1}$ resolution from $400-4,000 \mathrm{~cm}^{-1}$ with collection times of ca. $1 \mathrm{~min}$. Solid-state carbon-13 nuclear magnetic resonance $\left({ }^{13} \mathrm{C}-\mathrm{NMR}\right)$ spectra were acquired with an AMX400 NMR spectrometer (Bruker, Madison, WI, USA) at $100 \mathrm{MHz}$ under cross-polarisation while spinning at the magic angle. Power decoupling conditions were set with a $90^{\circ}$ pulse and a 4 s cycle time. The mechanical properties, including the tensile strength (TS) and elongation at break, of the dumbbell-shaped specimens (having dimensions specified by the ASTM D638 standard) were measured using a mechanical tester (Model LR5K; Lloyd Instruments, Bognor Regis, UK) at a crosshead speed of $10 \mathrm{~mm} \cdot \mathrm{min}^{-1}$. The mechanical properties of five specimens were determined, from which the mean values were calculated. Following failure, a thin section of the fracture plane was removed, coated with gold and imaged using scanning electron microscopy (SEM; Model S-1400; Hitachi, Tokyo, Japan) with an acceleration voltage of $15 \mathrm{kV}$ to observe the fracture surface morphology. The surface resistivity of a composite was measured using an Ohm-Stat RT1000 resistivity meter. The dimensions of the samples were $18.0 \times 10.0 \times 0.1 \mathrm{~cm}^{3}$.

\subsection{Thermal properties}

The phase transition behaviour was analysed by differential scanning calorimetry (DSC) (Model 2010; TA Instruments, New Castle, DE, USA). The thermal behaviour was investigated by thermogravimetric analysis (TGA) (Model 2010; TA Instruments). All experiments were carried out under an $\mathrm{N}_{2}$ atmosphere at a purge rate of $100 \mathrm{~mL} \cdot \mathrm{min}^{-1}$. A sample (ca. $5 \mathrm{mg}$ ) was placed in an aluminium crucible and tested with a thermal ramp, over a temperature range of $30-600^{\circ} \mathrm{C}$ at a heating rate of $10^{\circ} \mathrm{C} \cdot \mathrm{min}^{-1}$, and then the initial decomposition temperature (IDT) of the composite was determined. The heat deflection tem- 
perature (HDT) was determined according to the ASTM D648 standard using a dynamic mechanical analyser (DMA) (Model 2980; TA Instruments). A constant load of $0.46 \mathrm{MPa}$ was applied at the centre of a three-point bending flexural bar specimen. Then, the specimen was heated from room temperature to $150{ }^{\circ} \mathrm{C}$ at a rate of $2{ }^{\circ} \mathrm{C} / \mathrm{min}$ and the deflection was recorded as a function of temperature.

\subsection{Antimicrobial assay}

Escherichia coli (BCRC10239) and Staphylococcus aureus ((BCRC107801) were obtained from the Bioresource Collection and Research Centre, Hsinchu, Taiwan. The bacteria were maintained in nutrient broth (NB) medium ( $3 \mathrm{~g}$ of beef extract and $5 \mathrm{~g}$ of peptone in $1 \mathrm{~L}$ of distilled water, $\mathrm{pH}$ 7.0) and tryptic soy broth (TSB, Difco Lab, Becton-Dickinson Co., USA), respectively. The samples were incubated at $37 \pm 1{ }^{\circ} \mathrm{C}$ at a relative humidity of ca. $90 \%$.

$E$. coli and $S$. aureus were activated in the liquid medium and then transferred to fresh medium for $18 \mathrm{~h}$ of cultivation. The samples $(100 \mu \mathrm{L})$ were then dropped into the culture dish; a sterilised triangular glass rod was used to spread the bacteria in the dish. Additionally, the specimen $(c a .1 .35 \mathrm{~cm}$ in diameter and $0.05 \mathrm{~cm}$ thick) was wiped with $75 \%$ alcohol for sterilisation and placed in a culture dish with clippers. The culture dish edges were then sealed using sealing membrane and placed in an incubator, at $37 \pm 1^{\circ} \mathrm{C}$, for $24 \mathrm{~h}$ of cultivation to evaluate the bacterial inhibitory effects.

\section{Results and discussion}

\subsection{Structural analyses}

Figure 2 illustrates the FT-IR spectra of the MWCNTs and MWCNTs-COOH. Characteristic peaks of the MWCNTs appear at 1350 (C-O), 1480-1600 (aro-

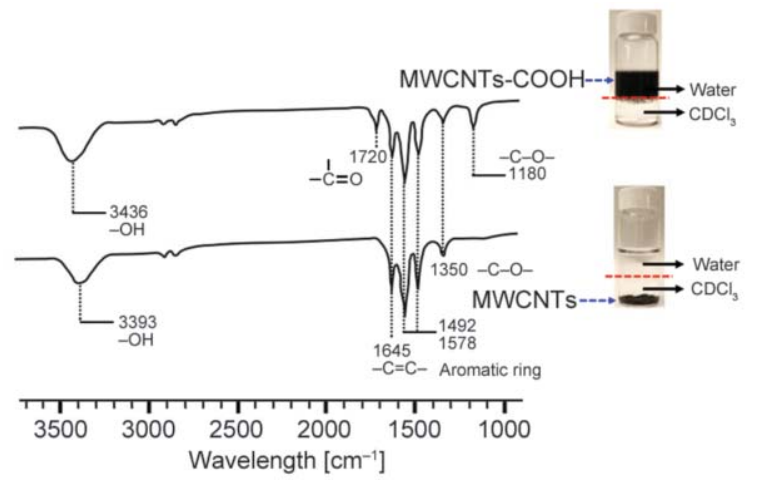

Figure 2. Fourier transform-infrared (FT-IR) spectra and dispersion of (a) MWCNTs and (b) chemically modified MWCNTs (MWCNTs-COOH) matic ring), $1645(\mathrm{C}=\mathrm{C})$ and $3393 \mathrm{~cm}^{-1}(-\mathrm{OH})$. The FT-IR spectrum of MWCNTs-COOH (Figure 2) shows two additional peaks at ca. 1180 and $1720 \mathrm{~cm}^{-1}$ that were assigned to the stretching vibrations of $\mathrm{C}=\mathrm{O}$ and $\mathrm{C}-\mathrm{O}$ groups in the carboxyl group $(-\mathrm{COOH})$, respectively. These results are in agreement with those of Jie et al. [34] and indicated that long ropes of MWCNTs were cleaved into short openended pipes, and that after the chemical oxidation treatment their tube-end sidewalls were also covered with oxygen-containing functional groups, such as $-\mathrm{COOH}$. The broad infrared absorption peak at $3393 \mathrm{~cm}^{-1}$ for the MWCNTs was shifted to $3436 \mathrm{~cm}^{-1}$ for the MWCNTs-COOH (Figure 2). This absorption was attributed to - $\mathrm{OH}$ groups in the MWCNTs and hydrogen bonding between those groups. The degree of hydrogen bonding was less because their absorption peak was shifted toward the position for free $-\mathrm{OH}$ groups [35].

Other observations confirmed the modification of the chemical structure of the MWCNTs. The MWCNTs or MWCNTs-COOH were dispersed in a $\mathrm{CDCl}_{3} /$ $\mathrm{H}_{2} \mathrm{O}$ solvent mixture, which on standing separated into upper $\left(\mathrm{H}_{2} \mathrm{O}\right)$ and lower $\left(\mathrm{CDCl}_{3}\right)$ phases. Pristine MWCNTs did not disperse in either solvent (Figure 2). Conversely, the relative hydrophilicity of MWCNTs-COOH significantly enhanced their dispersibility in water (Figure 2). The solubility of the hydrophobic chains of MWCNTs-COOH in water confirmed that carboxylic acid groups were grafted onto the MWCNTs [36].

The solid-state ${ }^{13} \mathrm{C}-\mathrm{NMR}$ spectra of PHA and PHA$g$-MA were also recorded; these spectra are shown in Figures 3a and 3b, respectively. Three peaks were observed that corresponded to carbon atoms in the unmodified PHA $(1,6: \delta=169.2 ; 2: \delta=38.7 ; 3: \delta=$ $71.8 ; 4: \delta=26.7 ; 5: \delta=9.5 ; 7: \delta=40.7 ; 8: \delta=67.6$; 9: $\delta=19.8 \mathrm{ppm}$ ) [37]. The ${ }^{13} \mathrm{C}-\mathrm{NMR}$ spectrum of PHA-g-MA showed additional peaks (11: $\delta=36.3$; $10: \delta=42.3 ; 12: \delta=172.1 \mathrm{ppm})$, thereby confirming that MA was covalently grafted onto the PHA [38]. Comparison of the solid-state ${ }^{13} \mathrm{C}$-NMR spectra of PHA/MWCNTs $(1.0 \mathrm{wt} \%)$ and PHA- $g$-MA/ MWCNTs-COOH (1.0 wt $\%)$ identified additional peaks at $\delta=36.3$ (11) and $\delta=42.3 \mathrm{ppm}$ (10) in the latter. As previously noted, peaks at locations 10 and 11 for PHA-g-MA were from MA grafted onto PHA. The peak at $\delta=172.1 \mathrm{ppm}$ corresponding to the $\mathrm{C}=\mathrm{O}$ carbon of PHA- $g$-MA (Figure 3b) was absent in the solid-state spectrum of PHA-g-MA/MWCNTs- 

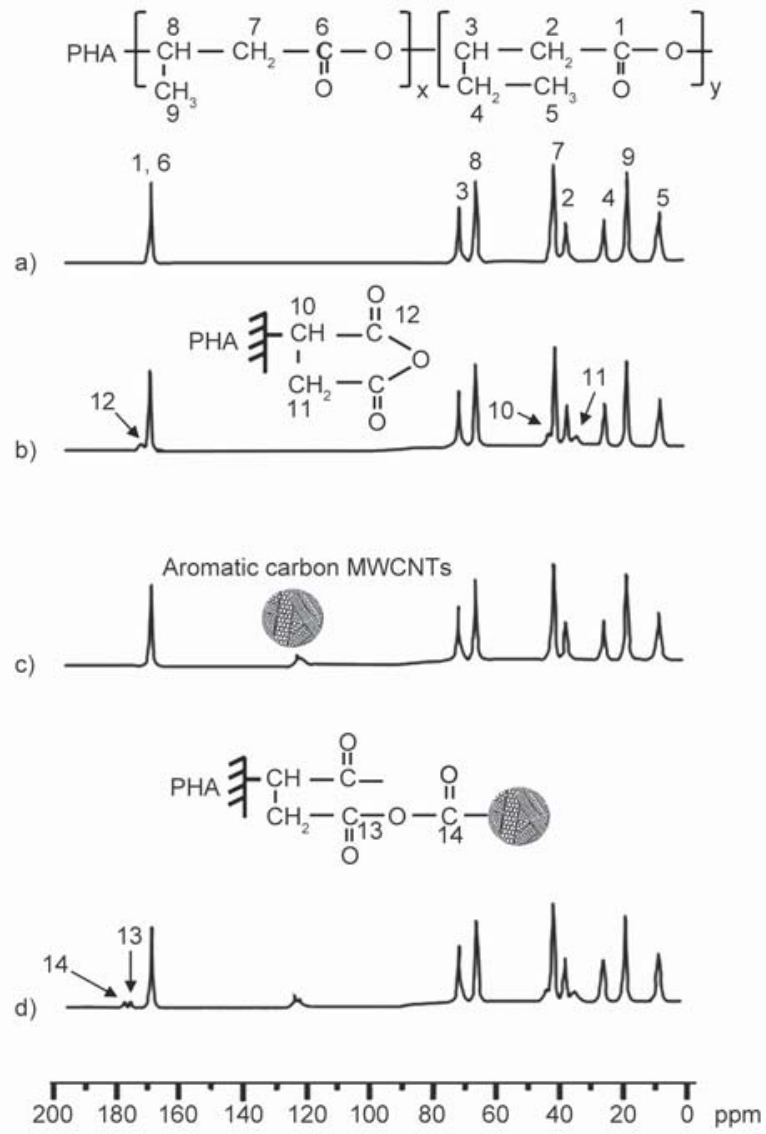

Figure 3. Solid-state carbon-13 nuclear magnetic resonance $\left({ }^{13} \mathrm{C}-\mathrm{NMR}\right)$ spectra of (a) neat PHA, (b) maleic anhydride (MA)-grafted polyhydroxyalkanoate (PHA-g-MA,) (c) PHA/MWCNTs $(1.0 \mathrm{wt} \%)$ and (d) PHA- $g$-MA/MWCNTs-COOH (1.0 wt $\%)$.

$\mathrm{COOH}(1.0 \mathrm{wt} \%)$ (Figure 3d); instead, four peaks appeared (13: $\delta=175.9$ and 14: $\delta=177.5 \mathrm{ppm})$. These five peaks are evidence of the condensation reaction between the anhydride carboxyl groups of PHA- $g$-MA and the - $\mathrm{COOH}$ groups of MWCNTs$\mathrm{COOH}$. Figure $3 \mathrm{c}$ shows that this reaction did not occur with PHA and MWCNTs.

\subsection{Phase morphology and mechanical properties}

SEM was used to evaluate the morphology of the composites and to examine the tensile fracture surfaces of PHA-g-MA/MWCNTs-COOH (1.0 wt $\%)$ and PHA- $g$-MA/MWCNTs-COOH (3.0 wt $\%$ ); the images are shown in Figures $4 \mathrm{a}$ and $4 \mathrm{~b}$. Individually embedded MWCNTs-COOH in the polymer matrix were very difficult to identify when the dispersion was poor and there was poor interfacial adhesion between the filler and the matrix; a lack of wettability can lead to agglomerated MWCNTs- $\mathrm{COOH}$ clusters.
Figures $4 \mathrm{a}$ and $4 \mathrm{~b}$ indicate that the MWCNTs$\mathrm{COOH}$ were well-dispersed in the polymer matrix for $1.0 \mathrm{wt} \%$ of MWCNTs-COOH but agglomerates were present for the $3.0 \mathrm{wt} \%$ MWCNTs-COOH.

Figures $4 \mathrm{c}$ and $4 \mathrm{~d}$ show the TS at failure and Young's modulus, respectively, for the PHA/MWCNTs and PHA- $g$-MA/MWCNTs-COOH composites as a function of MWCNTs or MWCNTs-COOH content. For the PHA/MWCNTs composites, the TS and Young's modulus value decreased with increasing MWCNTs or MWCNTs-COOH content because the interfacial force between the PHA and MWCNTs was only that of relatively weak hydrogen bonds. The PHA- $g$-MA/ MWCNTs-COOH composites exhibited much better TS and Young's modulus than the corresponding PHA/MWCNTs, although the PHA- $g$-MA had lower TS than pristine PHA. However, the TS (ranging from 15.9 to $32.2 \mathrm{MPa}$ ) and Young's modulus (ranging from 350.3 to $466.6 \mathrm{MPa}$ ) of PHA-g-MA/MWCNTs$\mathrm{COOH}$ increased with increasing MWCNTs- $\mathrm{COOH}$ content, up to $1.0 \mathrm{wt} \%$, and then decreased. Finally, for both grafted and non-grafted PHA composites, a maximum TS and Young's modulus could found as the filler content is $1 \mathrm{wt} \%$.

The positive effect on the TS and Young's modulus was attributed to the presence of immobilised or partially immobilised polymer phases [39], as well as the high aspect ratio and surface area of the carbon nanotubes, nanoscale dispersion of MWCNTs- $\mathrm{COOH}$ layers in the polymer matrix and the formation of chemical bonds through the condensation reaction between PHA-g-MA and MWCNTs-COOH. For a MWCNTs-COOH content above $1.0 \mathrm{wt} \%$, the decrease in TS and Young's modulus was attributed to aggregation of the MWCNTs-COOH.

\subsection{Thermal properties}

Table 1 shows the DSC results for samples recorded during heating scans at $10^{\circ} \mathrm{C} \cdot \mathrm{min}^{-1}$. The glass transition temperatures $\left(T_{\mathrm{g}}\left[{ }^{\circ} \mathrm{C}\right]\right)$, melting temperatures $\left(T_{\mathrm{m}}\left[{ }^{\circ} \mathrm{C}\right]\right)$ and heats of fusion $\left(\Delta H_{\mathrm{f}}\left[\mathrm{J} \cdot \mathrm{g}^{-1}\right]\right)$ were associated with endothermic transitions. The $T_{\mathrm{g}}$ increased with increasing MWCNTs or MWCNTs$\mathrm{COOH}$ content for the PHA/MWCNTs and PHA-gMA/MWCNTs-COOH composites (Table 1). This increase likely resulted from the reduced space available for molecular motion with increasing MWCNTs or MWCNTs-COOH content [40]. At the same filler content, Table 1 also shows that the $T_{\mathrm{g}}$ of PHA- $g$-MA/ MWCNTs-COOH was higher than that of PHA/ 


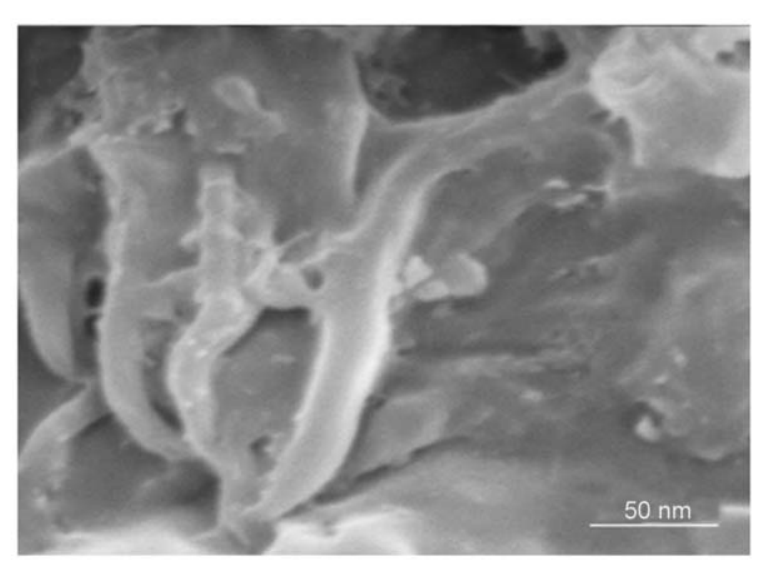

a)

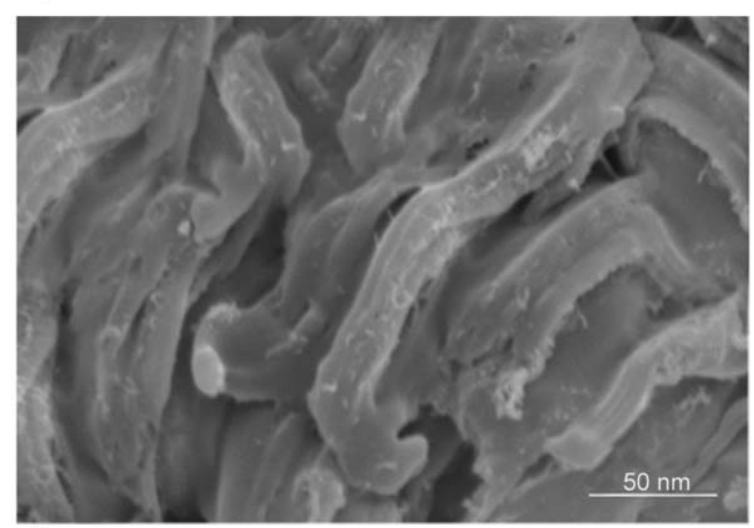

b)

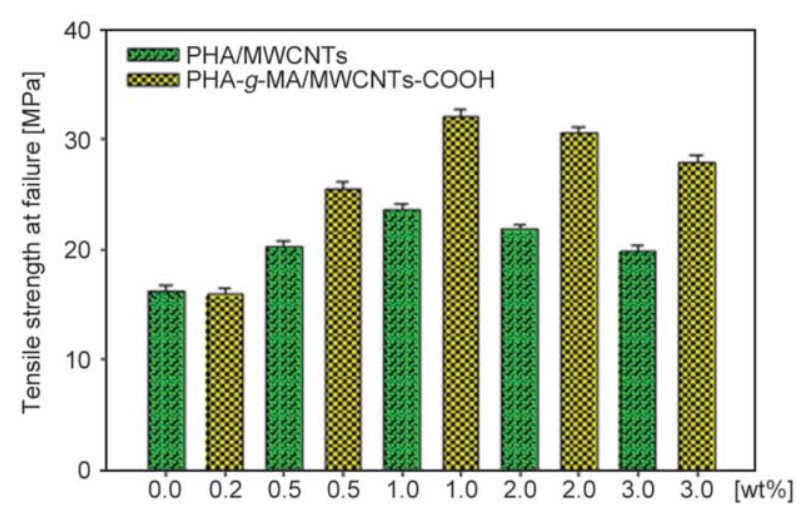

c)

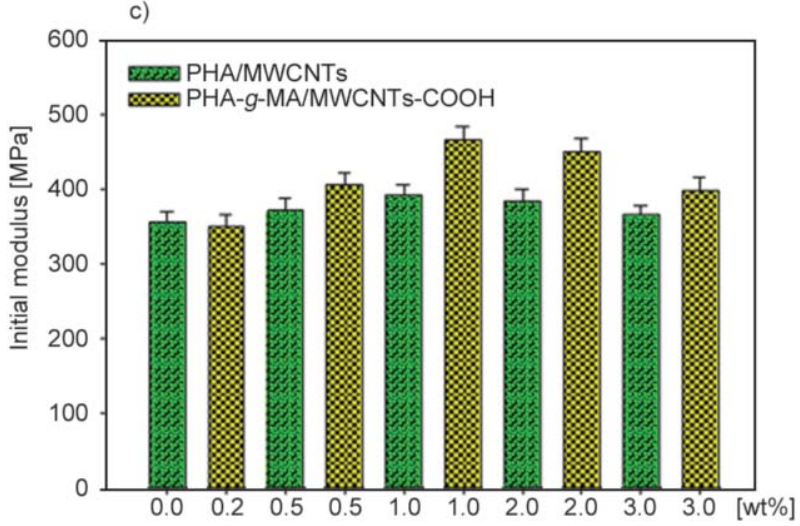

d)

Figure 4. Scanning electron microscopy (SEM) images of the PHA-g-MA/MWCNTs-COOH composites with different MWCNTs-COOH contents: (a) $1.0 \mathrm{wt} \%$ and (b) $3.0 \mathrm{wt} \%$. Effect of MWCNTs or MWCNTs-COOH content on the tensile strength at failure (c) and Young's modulus (d) of the PHA/MWCNTs and PHA-g-MA/MWCNTs-COOH composites.

MWCNTs. The greater enhancement in the $T_{\mathrm{g}}$ for the PHA-g-MA/MWCNTs-COOH composites may be because of the formation of chemical bonds via the condensation reaction between PHA- $g$-MA and MWCNTs-COOH, since these strong bonds would be able to hinder the motion of the polymer chains. For the PHA/MWCNTs composites, the improvement in $T_{\mathrm{g}}$ was slight because the MWCNTs were physically dispersed in the PHA matrix. The $T_{\mathrm{g}}$ of the PHA-g-MA/MWCNTs-COOH composites increased with increasing MWCNTs-COOH content, to a maximum value at $1.0 \mathrm{wt} \%$, and then decreased.
With a MWCNTs-COOH content above $1.0 \mathrm{wt} \%$, the excess fillers were physically dispersed in the polymer matrix. Such excess MWCNTs-COOH induced agglomerates of the inorganic phases and reduced their compatibility, causing the slight enhancement of the $T_{\mathrm{g}}$.

Table 1 also shows that the addition of inorganic filler (MWCNTs or MWCNTs-COOH) reduced the $T_{\mathrm{m}}$ for both composites and that the lowest $T_{\mathrm{m}}$ occurred at $1.0 \mathrm{wt} \%$. Notably, at the same filler content, all of the PHA-g-MA/MWCNTs-COOH composites had lower $T_{\mathrm{m}}$ values than their PHA/MWCNTs coun-

Table 1. DSC characterisation of the PHA/MWCNTs and PHA-g-MA/MWCNTs-COOH composites ${ }^{\mathrm{a}}$ the mean value of three examination for each sample

\begin{tabular}{|c|c|c|c|c|c|c|}
\hline \multirow{2}{*}{$\begin{array}{c}\text { MWCNTs-COOH or } \\
\text { MWCNTs } \\
{[\mathbf{w t} \%]}\end{array}$} & \multicolumn{3}{|c|}{ PHA/MWCNTs } & \multicolumn{3}{|c|}{ PHA-g-MA/MWCNTs-COOH } \\
\cline { 2 - 7 } & $\begin{array}{c}\boldsymbol{T}_{\mathbf{g}} \\
{\left[{ }^{\circ} \mathbf{C}\right]}\end{array}$ & $\begin{array}{c}\boldsymbol{T}_{\mathbf{m}} \\
{\left[{ }^{\circ} \mathbf{C}\right]^{\mathbf{a}}}\end{array}$ & $\begin{array}{c}\Delta \boldsymbol{H}_{\mathbf{m}} \\
{\left[\mathbf{J}^{-1} \cdot \mathbf{g}^{-1}\right]}\end{array}$ & $\begin{array}{c}\boldsymbol{T}_{\mathbf{g}} \\
{\left[{ }^{\circ} \mathbf{C}\right]}\end{array}$ & $\begin{array}{c}\boldsymbol{T}_{\mathbf{m}} \\
{\left[{ }^{\circ} \mathbf{C}\right]^{\mathbf{a}}}\end{array}$ & $\begin{array}{c}\Delta \boldsymbol{H}_{\mathbf{m}} \\
{\left[\mathbf{J} \cdot \mathbf{g}^{-1}\right]}\end{array}$ \\
\hline 0.0 & -10 & $135.6 \pm 0.3$ & 36.7 & -9 & $135.2 \pm 0.2$ & 35.9 \\
\hline 0.5 & -6 & $135.0 \pm 0.2$ & 32.5 & -4 & $134.1 \pm 0.3$ & 34.5 \\
\hline 1.0 & -4 & $134.2 \pm 0.3$ & 29.8 & 2 & $133.1 \pm 0.3$ & 32.9 \\
\hline 2.0 & -5 & $134.5 \pm 0.4$ & 27.6 & 1 & $133.5 \pm 0.4$ & 32.0 \\
\hline 3.0 & -6 & $134.8 \pm 0.4$ & 26.5 & -2 & $133.9 \pm 0.3$ & 31.5 \\
\hline
\end{tabular}


terparts. This lower $T_{\mathrm{m}}$ for PHA- $g$-MA/MWCNTs$\mathrm{COOH}$ made it a more easily processed blend. The $\Delta H_{\mathrm{m}}$ of a polymer is a measure of its crystallinity. For both composites (PHA/MWCNTs and PHA-gMA/MWCNTs-COOH), their melting enthalpies decreased with increasing MWCNTs or MWCNTs$\mathrm{COOH}$ content. The lower degree of crystallisation was probably caused by increased difficulty in rearranging the polymer chains, because the MWCNTs or MWCNTs-COOH restricted movement of the polymer segments. Additionally, the $\Delta H_{\mathrm{m}}$ of PHA$g$-MA $\left(36.7 \mathrm{~J} \cdot \mathrm{g}^{-1}\right)$ was lower than that of neat PHA $\left(35.9 \mathrm{~J} \mathrm{~J} \cdot \mathrm{g}^{-1}\right)$ but those of the PHA- $g$-MA/MWCNTs$\mathrm{COOH}$ composites were $c a$. 2-5 $\mathrm{J} \cdot \mathrm{g}^{-1}$ higher than the corresponding PHA/MWCNTs ones. This behaviour was caused by the formation of the ester functional group from the reaction between the $-\mathrm{COOH}$ group of MWCNTs- $\mathrm{COOH}$ and the MA group of PHA- $g$-MA.

The IDTs of PHA, PHA-g-MA, MWCNTs and MWCNTs-COOH, and the composites at constant weight loss $(5 \%)$, were all higher than those of pristine PHA because of the carbon nanotubes. For the composites, the IDTs increased with increasing MWCNTs or MWCNTs-COOH content. This result was attributed to a looser PHA or PHA- $g$-MA polymer structure by the expansion of MWCNTs or MWCNTs-COOH, and the very high IDTs of carbon nanotube. For the same MWCNTs or MWCNTs$\mathrm{COOH}$ content, the PHA/MWCNTs composites had lower IDTs than the PHA-g-MA/MWCNTs-COOH composites (Figure 5 and Table 2). The lower IDTs of the PHA/MWCNTs composites were attributed to two factors: increased inhibition of movement of polymer chains by the MWCNTs and/or the condensation reaction, which led to increased adhesion of MWCNTs-COOH in PHA-g-MA compared with PHA/MWCNTs. These results are similar to those obtained for other polymer composites with carbon nanotubes and are a consequence of the difference

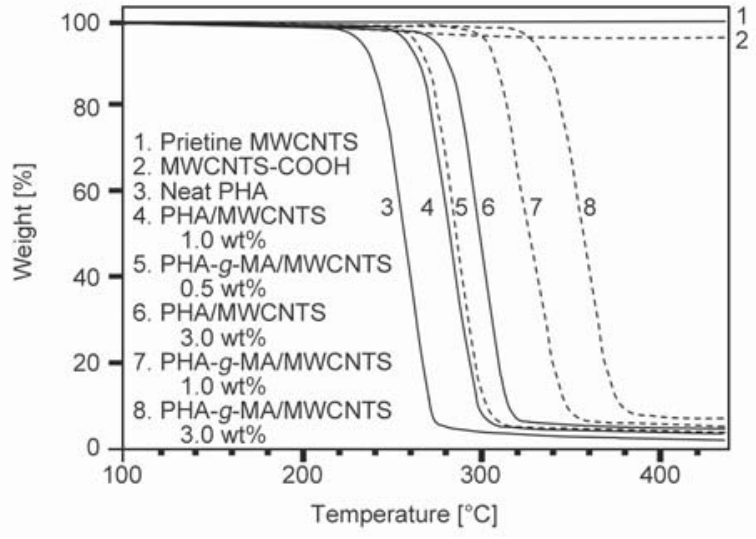

Figure 5. Thermogravimetric analysis (TGA) curves for MWCNTs, MWCNTs-COOH, PHA, PHA/ MWCNTs and PHA-g-MA/MWCNTs-COOH composites

in interfacial forces. The PHA-g-MA/MWCNTs$\mathrm{COOH}$ composites have strong coordination sites, associated with the presence of the MA groups and the $-\mathrm{COOH}$ group of the MWCNTs- $\mathrm{COOH}$ [41]. The IDTs for the PHA-g-MA/MWCNTs-COOH composites were ca. $17-48^{\circ} \mathrm{C}$ higher than those of the analogous PHA/MWCNTs composites. A comparison between PHA- $g$-MA and the PHA- $g$-MA/ MWCNTs-COOH composites showed that the increment in IDTs was ca. $76^{\circ} \mathrm{C}$ with $1.0 \mathrm{wt} \%$ MWCNTs$\mathrm{COOH}$ but only ca. $23^{\circ} \mathrm{C}$ at $3.0 \mathrm{wt} \%$. This result further confirmed that the optimal loading of MWCNTs$\mathrm{COOH}$ was $1 \mathrm{wt} \%$, because excess MWCNTs-COOH caused separation of the organic and inorganic phases and impaired their compatibility and dispersibility.

Furthermore, the char residual yields of the PHA-gMA/MWCNTs-COOH composites increased with increasing MWCNTs-COOH content, indicating that thermal decomposition of the polymer matrix was retarded in the PHA- $g$-MA/MWCNTs-COOH composites. This result may be attributed to a combined effect, i.e. the MWCNTs-COOH could prevent the transport of decomposition products in the polymer composites. As reported previously, the thermal sta-

Table 2. Effect of MWCNTs or MWCNTs-COOH content on the initial decomposition temperature (IDTs) and heat deflection temperature (HDT) of PHA/MWCNTs and PHA- $g$-MA/MWCNTs-COOH

\begin{tabular}{|c|c|c|c|c|c|c|}
\hline $\begin{array}{c}\text { MWCNTs-COOH or } \\
\text { MWCNTs } \\
{[\mathbf{w t} \%]}\end{array}$ & \multicolumn{3}{|c|}{ PHA/MWCNTs } & \multicolumn{3}{|c|}{ PHA-g-MA/MWCNTs-COOH } \\
\cline { 2 - 7 } & $\begin{array}{c}\text { IDT (5\%) } \\
{\left[{ }^{\circ} \mathbf{C}\right]}\end{array}$ & $\begin{array}{c}\text { HDT } \\
{\left[{ }^{\circ} \mathbf{C}\right]}\end{array}$ & $\begin{array}{c}\text { Char residue }\left(\mathbf{4 0 0}^{\circ} \mathbf{C}\right) \\
{[\mathbf{5 \%}]}\end{array}$ & $\begin{array}{c}\text { IDT (5\%) } \\
{\left[{ }^{\circ} \mathbf{C}\right]}\end{array}$ & $\begin{array}{c}\text { HDT } \\
{\left[{ }^{\circ} \mathbf{C}\right]}\end{array}$ & $\begin{array}{c}\text { Char residue (400 } \\
{\left[\mathbf{5}^{\circ} \mathbf{C}\right)}\end{array}$ \\
\hline 0.0 & 231 & 89.2 & 0.8 & 227 & 88.6 & 0.6 \\
\hline 0.5 & 245 & 93.8 & 1.5 & 262 & 96.1 & 2.1 \\
\hline 1.0 & 261 & 97.6 & 2.9 & 303 & 105.1 & 4.3 \\
\hline 2.0 & 270 & 98.6 & 4.1 & 316 & 107.0 & 5.9 \\
\hline 3.0 & 278 & 99.3 & 5.5 & 326 & 108.1 & 7.2 \\
\hline
\end{tabular}


bility of polymer/MWCNTs composites can promote the formation of a char layer and form a MWCNTs network structure that reduces the diffusion of volatile combustible fragments generated by polymer degradation [42]. Therefore, the TGA results demonstrated that the incorporation of a small quantity of MWCNTs-COOH could significantly improve the thermal stability of the PHA-g-MA/MWCNTs-COOH composites.

The HDT is an important indicator of the heat resistance of plastics and composites under an applied load [43]. The value indicates the upper service temperature limit for the material. Table 2 shows that the HDT of the PHA/MWCNTs and PHA- $g$-MA/MWCNTs-COOH composites were slightly higher compared with that of PHA. This improvement was attributed to the enhanced interfacial adhesion between the matrix and the carbon nanotubes. Table 2 indicates that the PHA-g-MA/MWCNTs-COOH composites had higher HDT than the corresponding PHA/ MWCNTs ones. The higher heat resistance of the PHA-g-MA/MWCNTs-COOH composites might also be related to the formation of stronger chemical bonds between the PHA-g-MA and MWCNTs- $\mathrm{COOH}$, which prevented deformation.

\subsection{Electrical properties}

The surface resistivity slowly decreased as the carbon nanotube content increased in low carbon nanotube-content composites. A large proportion of the electrons of the applied field tunnel through the insulating layer when carbon nanotubes are present. Figure 6 presents the surface resistivity of the PHA/ MWCNTs and PHA- $g$-MA/MWCNTs-COOH composites. The surface resistivity of PHA or PHA- $g$ MA was greater than $10^{14} \Omega \cdot \mathrm{sq}^{-1}$ and the value for the composite decreased as the MWCNTs or MWCNTs$\mathrm{COOH}$ content increased [44]. A marked decrease was observed in the electrical resistivity with increasing MWCNTs-COOH content, up to $1.0 \mathrm{wt} \%$, above which the electrical resistivity slightly decreased. The reduced electrical resistivity of the PHA$g$-MA/MWCNTs-COOH composites was likely caused by inhibited polymer motion, which would have restricted the chain rearrangement and reorganisation required for solidification. As expected, all of the PHA/MWCNTs and PHA- $g$-MA/MWCNTs$\mathrm{COOH}$ composites had lower electrical resistivities than pristine PHA and PHA-g-MA. The decrease in the electrical resistivity was greater for the PHA-g-

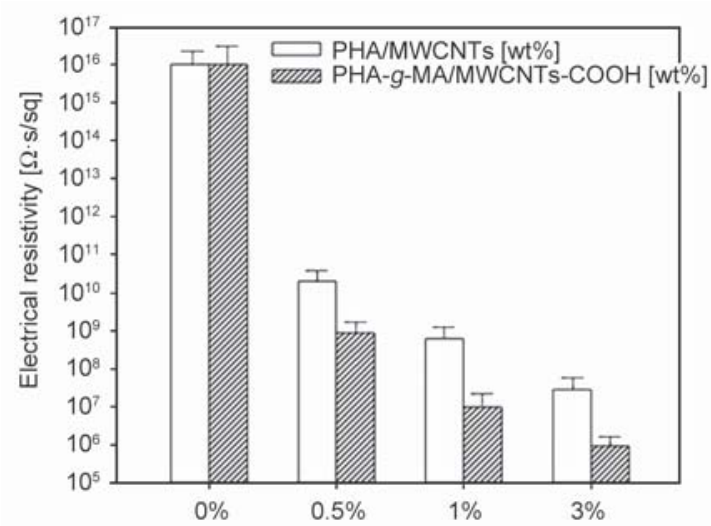

Figure 6. Electrical resistivity of PHA and PHA- $g$-MA, and the PHA/MWCNTs and PHA- $g$-MA/MWCNTs$\mathrm{COOH}$ composites

MA/MWCNTs-COOH composites than for the PHA/ MWCNTs composites, presumably because of ester bond formation, as previously discussed. Ester linkages are stronger than the hydrogen bonds formed in PHA/MWCNTs composites and therefore are more effective at hindering polymer motion. Moreover, the electrical resistivities of all of the PHA-g-MA/ MWCNTs-COOH composites were lower than those of their PHA/MWCNTs composite counterparts. This lower resistivity allowed the PHA- $g$-MA/MWCNTs$\mathrm{COOH}$ composites to more easily form an interconnected conductive pathway throughout the material. The lower observed resistivity in the $1.0 \mathrm{wt} \% \mathrm{com}-$ posites implied that an excess amount of MWCNTs or MWCNTs-COOH was present at levels $>1.0 \mathrm{wt} \%$ and was physically dispersed throughout the polymer matrix. This excess of MWCNTs or MWCNTs$\mathrm{COOH}$ may have led to aggregate formation between the organic and inorganic phases, thereby lessening compatibility with the matrix in the PHA/ MWCNTs and PHA-g-MA/MWCNTs-COOH composites.

Figure 6 shows the results for the various PHA/MWCNTs and PHA- $g$-MA/MWCNTs-COOH composites; the lowest resistivities were $6.3 \cdot 10^{8}$ and $9.8 \cdot 10^{6} \Omega \cdot \mathrm{sq}^{-1}$, respectively. In general, an electrical resistance between $10^{5}$ and $10^{12} \Omega \cdot \mathrm{sq}^{-1}$ indicates antistatic behaviour [45]. Figure 7 shows the results of antistatic testing with pristine PHA and $0.5-3.0 \mathrm{wt} \%$ PHA-g-MA/MWCNTs-COOH filaments (sample size: length $=50.00 \pm 0.20 \mathrm{~mm}$ and diameter $=$ $1.75 \pm 0.05 \mathrm{~mm}$ ). Each 3D printing filament was rubbed and then immersed in small expanded polystyrene balls. Any adsorption of plastic balls indicated the presence of static electricity. The pristine PHA filaments adsorbed a significant number of the plastic 


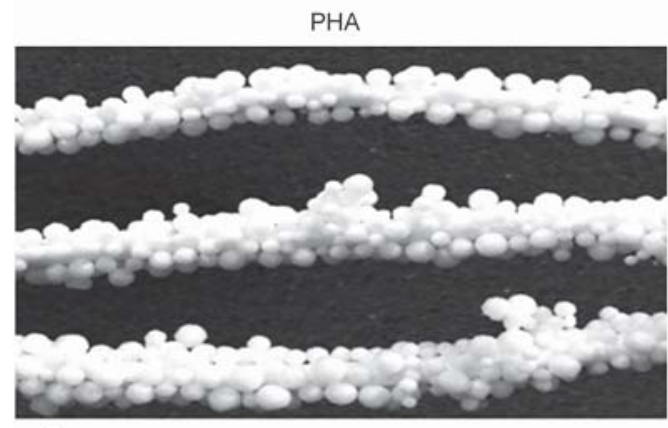

a)

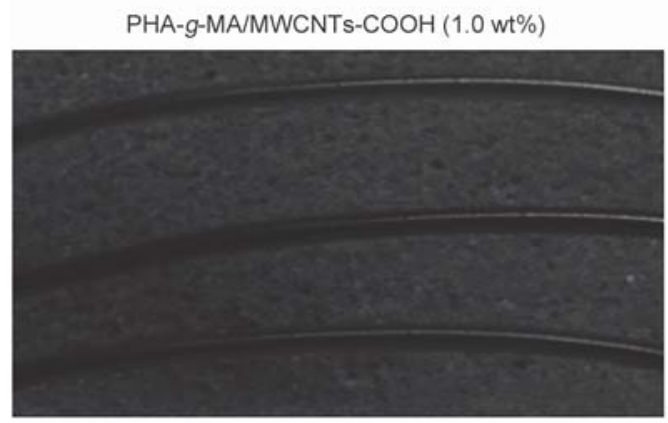

c)

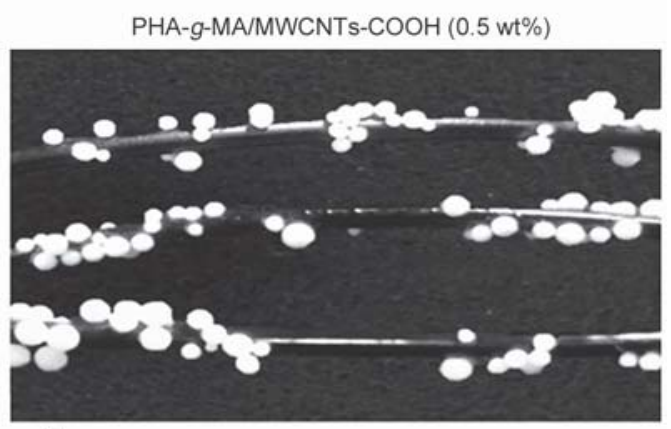

b)

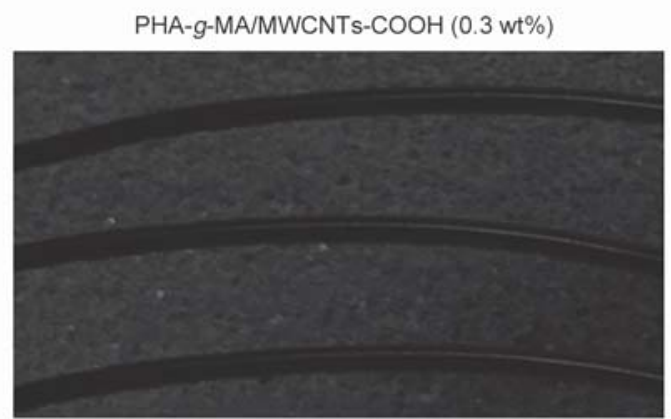

d)

Figure 7. Antistatic properties of (a) PHA, (b) PHA-g-MA/MWCNTs-COOH (0.5 wt\%), (c) PHA-g-MA/MWCNTs-COOH $(1.0 \mathrm{wt} \%)$ and (d) PHA- $g$-MA/MWCNTs-COOH (3.0 wt $\%)$ filaments

balls. At the $0.5 \%$ level, the PHA- $g$-MA/MWCNTs$\mathrm{COOH}$ filaments adsorbed fewer expanded polystyrene balls, whereas the filaments were clean at levels above $1.0 \mathrm{wt} \%$. Thus, the addition of or MWCNTs-COOH to the composites improved the electrostatic dissipative properties of the bulk material.

\subsection{Antibacterial activity}

Gram-positive bacteria (S. aureus) and Gram-negative bacteria (E. coli) cultures with PHA, PHA/MWCNTs and PHA/MWCNTs-COOH were chosen as the bacterial standards for determining the antibacterial properties of the composite materials. Figure 8 shows that the PHA membrane lacking MWCNTs displayed no antibacterial zones. However, some micro-sized antibacterial zones were found in the PHA/MWCNTs and PHA- $g$-MA/MWCNTs-COOH membrane specimens containing as little as $1.0 \mathrm{wt} \%$ MWCNTs or MWCNTs-COOH; the antibacterial zones became more apparent with increasing MWCNTs or MWCNTs-COOH content. Thus, the PHA/MWCNTs or PHA-g-MA/MWCNTs-COOH membranes displayed an antibacterial effect because of the incorporation of the MWCNTs or MWCNTs$\mathrm{COOH}$ [46]. Moreover, the antibacterial zones of the PHA-g-MA/MWCNTs-COOH membranes were

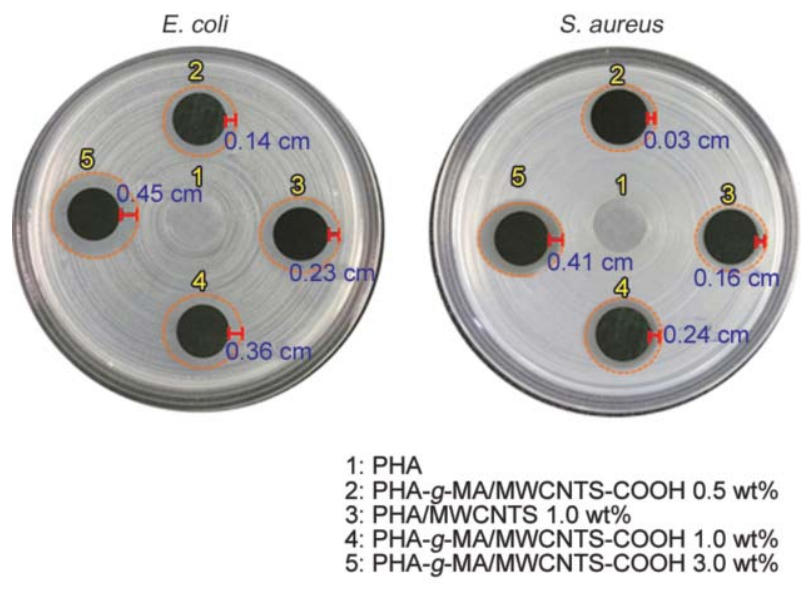

Figure 8. Exposure course of the inhibition zones of E. coli and $S$. aureus cells during exposure to PHA or PHA- $g$-MA and their composite surfaces

larger than those of the PHA/MWCNTs membranes. The antibacterial effect was enhanced in the PHA$g$-MA/MWCNTs-COOH membranes because the PHA- $g$-MA was stabilised in a fixed orientation by the MWCNTs-COOH. This orientation resulted in bacterial death because of increasing effective concentration of the MWCNTs-COOH or a longer contact time with the bacteria. According to Figure 8, the inhibition zone of the PHA/MWCNTs or PHA$g$-MA/MWCNTs-COOH series composite on E. coli 
was greater than that on S. aureus; this was because the Gram-positive bacteria structure has thick peptidoglycan cells [47].

\section{Conclusions}

Oxidised MWCNTs (MWCNTs-COOH) were successfully combined with PHA- $g$-MA by a transesterification procedure and $3 \mathrm{D}$ printing filaments were fabricated from the composites. The strong interaction of the nanotubes with the PHA matrix in the PHA- $g$-MA/MWCNTs-COOH composites led to improved mechanical, thermal, conductive, antistatic and antibacterial performances. At the $1.0 \mathrm{wt} \%$ incorporation level, the IDT of the composite was $72^{\circ} \mathrm{C}$ higher than that of pristine PHA. The TSs at failure and the Young's modulus of the composites were enhanced by 16.0 and $110 \mathrm{MPa}$, respectively. Moreover, the electrical resistivity of the PHA-g-MA/ MWCNTs-COOH $(1.0 \mathrm{wt} \%)$ composite was $9.8 \cdot 10^{6} \Omega \cdot \mathrm{sq}^{-1}$, which is $10^{8}$ fold lower than that of neat PHA. This provided a high antistatic effect. Antibacterial activity was enhanced with the addition of $1.0 \mathrm{wt} \%$ of MWCNTs-COOH to PHA- $g$-MA, resulting in large antibacterial zones. Thus, the current study demonstrated improved compatibilisation between PHA and MWCNTs, with subsequent enhanced antibacterial and antistatic properties.

\section{Acknowledgements}

The author thanks the Ministry of Science and Technology (Taipei City, Taiwan, R.O.C.) for financial support (MOST 104-2221-E-244-011-)

\section{References}

[1] Ding S., Cargill A. A., Das S. R., Medintz I. L., Claussen J. C.: Biosensing with Förster resonance energy transfer coupling between fluorophores and nanocarbon allotropes. Sensors, 15, 14766-14787 (2015). https://doi.org/10.3390/s150614766

[2] Bayram B., Akyilmaz E.: Development of a new microbial biosensor based on conductive polymer/multiwalled carbon nanotube and its application to paracetamol determination. Sensors and Actuators B: Chemical, 233, 409-418 (2016). https://doi.org/10.1016/j.snb.2016.04.029

[3] Kaseem M., Hamad K., Ko Y. G.: Fabrication and materials properties of polystyrene/carbon nanotube (PS/ CNT) composites: A review. European Polymer Journal, 79, 36-62 (2016).

https://doi.org/10.1016/j.eurpolymj.2016.04.011
[4] Mallakpour S., Khadem E.: Carbon nanotube-metal oxide nanocomposites: Fabrication, properties and applications. Chemical Engineering Journal, 302, 344367 (2016).

https://doi.org/10.1016/j.cej.2016.05.038

[5] Mittal G., Dhand V., Rhee K. Y., Park S-J., Lee W. R.: A review on carbon nanotubes and graphene as fillers in reinforced polymer nanocomposites. Journal of Industrial and Engineering Chemistry, 21, 11-25 (2015). https://doi.org/10.1016/j.jiec.2014.03.022

[6] Tkalya E. E., Ghislandi M., de With G., Koning C. E.: The use of surfactants for dispersing carbon nanotubes and graphene to make conductive nanocomposites. Current Opinion in Colloid and Interface Science, 17, 225232 (2012).

https://doi.org/10.1016/j.cocis.2012.03.001

[7] Rusman N. A. A., Dahari M.: A review on the current progress of metal hydrides material for solid-state hydrogen storage applications. International Journal of Hydrogen Energy, 41, 12108-12126 (2016). https://doi.org/10.1016/j.ijhydene.2016.05.244

[8] Chen L., He H., Yu H., Cao Y., Lei D., Menggen Q., Wu M., Hu L.: Electron field emission characteristics of graphene/carbon nanotubes hybrid field emitter. Journal of Alloys and Compounds, 610, 659-664 (2014). https://doi.org/10.1016/j.jallcom.2014.04.202

[9] Daver F., Baez E., Shanks R. A., Brandt M.: Conductive polyolefin-rubber nanocomposites with carbon nanotubes. Composites Part A: Applied Science and Manufacturing, 80, 13-20 (2016).

https://doi.org/10.1016/j.compositesa.2015.10.002

[10] Wang C. X., Lv J. C., Ren T., Zhi T., Chen J. Y., Zhou Q. Q., Lu Z. Q., Gao D. W., Jin L. M.: Surface modification of polyester fabric with plasma pretreatment and carbon nanotube coating for antistatic property improvement. Applied Surface Science, 359, 196-203 (2015). https://doi.org/10.1016/j.apsusc.2015.10.060

[11] Gorrasi G., Milone C., Piperopoulos E., Lanza M., Sorrentino A.: Hybrid clay mineral-carbon nanotube-PLA nanocomposite films. Preparation and photodegradation effect on their mechanical, thermal and electrical properties. Applied Clay Science, 71, 49-54 (2013). https://doi.org/10.1016/j.clay.2012.11.004

[12] Puértolas J. A., Kurtz S. M.: Evaluation of carbon nanotubes and graphene as reinforcements for UHMWPEbased composites in arthroplastic applications: A review. Journal of the Mechanical Behavior of Biomedical Materials, 39, 129-145 (2014). https://doi.org/10.1016/j.jmbbm.2014.06.013

[13] Díez-Pascual A. M., Naffakh M., Marco C., GómezFatou M. A., Ellis G. J.: Multiscale fiber-reinforced thermoplastic composites incorporating carbon nanotubes: A review. Current Opinion in Solid State and Materials Science, 18, 62-80 (2014). https://doi.org/10.1016/j.cossms.2013.06.003 
[14] Rossi V., Cleeve-Edwards N., Lundquist L., Schenker U., Dubois C., Humbert S., Jolliet O.: Life cycle assessment of end-of-life options for two biodegradable packaging materials: Sound application of the European waste hierarchy. Journal of Cleaner Production, 86, 132-145 (2015).

https://doi.org/10.1016/j.jclepro.2014.08.049

[15] Wang Y., Yin J., Chen G-Q.: Polyhydroxyalkanoates, challenges and opportunities. Current Opinion in Biotechnology, 30, 59-65 (2014).

https://doi.org/10.1016/j.copbio.2014.06.001

[16] Chanprateep S.: Current trends in biodegradable polyhydroxyalkanoates. Journal of Bioscience and Bioengineering, 110, 621-632 (2010).

https://doi.org/10.1016/j.jbiosc.2010.07.014

[17] Keshavarz T., Roy I.: Polyhydroxyalkanoates: Bioplastics with a green agenda. Current Opinion in Microbiology, 13, 321-326 (2010).

https://doi.org/10.1016/j.mib.2010.02.006

[18] Brzezinski M., Bogusławska M., Ilčíková M., Mosnaček J., Biela T.: Unusual thermal properties of polylactides and polylactide stereocomplexes containing polylactide-functionalized multi-walled carbon nanotubes. Macromolecules, 45, 8714-8721 (2012).

https://doi.org/10.1021/ma301554q

[19] Brzeziński M., Biela T.: Polylactide nanocomposites with functionalized carbon nanotubes and their stereocomplexes: A focused review. Materials Letters, 121, 244-250 (2014).

https://doi.org/10.1016/j.matlet.2014.01.159

[20] Chen C-M., Chen M., Leu F-C., Hsu S-Y., Wang S-C., Shi S-C., Chen C-F.: Purification of multi-walled carbon nanotubes by microwave digestion method. Diamond and Related Materials, 13, 1182-1186 (2004). https://doi.org/10.1016/j.diamond.2003.11.016

[21] Xiong X., Zhou L., Yu G., Yang K., Ye M., Xia Q.: Synthesis and catalytic performance of a novel RuCuNi/ CNTs nanocomposite in hydrolytic dehydrogenation of ammonia borane. International Journal of Hydrogen Energy, 40, 15521-15528 (2015).

https://doi.org/10.1016/j.ijhydene.2015.09.095

[22] Bajada G. S., Tiwari S. K., Vijayakumar R. P.: Synthesis and characterization of CNTs using polypropylene waste as precursor. Materials Science and Engineering: B, 194, 68-77 (2015).

https://doi.org/10.1016/j.mseb.2015.01.004

[23] Gebler M., Uiterkamp A. J. M. S., Visser C.: A global sustainability perspective on 3D printing technologies. Energy Policy, 74, 158-167 (2014).

https://doi.org/10.1016/j.enpol.2014.08.033

[24] Rayna T., Striukova L.: From rapid prototyping to home fabrication: How 3D printing is changing business model innovation. Technological Forecasting and Social Change, 102, 214-224 (2016).

https://doi.org/10.1016/j.techfore.2015.07.023
[25] Stansbury J. W., Idacavage M. J.: 3D printing with polymers: Challenges among expanding options and opportunities. Dental Materials, 32, 54-64 (2016).

https://doi.org/10.1016/j.dental.2015.09.018

[26] Weng Z., Wang J., Senthil T., Wu L.: Mechanical and thermal properties of ABS/montmorillonite nanocomposites for fused deposition modeling 3D printing. Materials and Design, 102, 276-283 (2016).

https://doi.org/10.1016/j.matdes.2016.04.045

[27] Deng Y., Cao S-J., Chen A., Guo Y.: The impact of manufacturing parameters on submicron particle emissions from a desktop 3D printer in the perspective of emission reduction. Building and Environment, 104, 311319 (2016).

https://doi.org/10.1016/j.buildenv.2016.05.021

[28] Mohammed J. S.: Applications of 3D printing technologies in oceanography. Methods in Oceanography, 17, 97-117 (2016).

https://doi.org/10.1016/j.mio.2016.08.001

[29] McCullough E. J., Yadavalli V. K.: Surface modification of fused deposition modeling ABS to enable rapid prototyping of biomedical microdevices. Journal of Materials Processing Technology, 213, 947-954 (2013). https://doi.org/10.1016/j.jmatprotec.2012.12.015

[30] Postiglione G., Natale G., Griffini G., Levi M., Turri S.: Conductive $3 \mathrm{D}$ microstructures by direct 3D printing of polymer/carbon nanotube nanocomposites via liquid deposition modeling. Composites Part A: Applied Science and Manufacturing, 76, 110-114 (2015). https://doi.org/10.1016/j.compositesa.2015.05.014

[31] Guo S-Z., Yang X., Heuzey M-C., Therriault D.: 3D printing of a multifunctional nanocomposite helical liquid sensor. Nanoscale 2015, 6451-6456 (2015). https://doi.org/10.1039/C5NR00278H

[32] Wu C-S.: Influence of modified polyester on the material properties of collagen-based biocomposites and in vitro evaluation of cytocompatibility. Materials Science and Engineering: C, 48, 310-319 (2015).

https://doi.org/10.1016/j.msec.2014.12.013

[33] Wu C-S.: Modulation, functionality, and cytocompatibility of three-dimensional printing materials made from chitosan-based polysaccharide composites. Materials Science and Engineering: C, 69, 27-36 (2016). https://doi.org/10.1016/j.msec.2016.06.062

[34] Jie G., Kongyin Z., Xinxin Z., Zhijiang C., Min C., Tian C., Junfu W.: Preparation and characterization of carboxyl multi-walled carbon nanotubes/calcium alginate composite hydrogel nano-filtration membrane. Materials Letters, 157, 112-115 (2015). https://doi.org/10.1016/j.matlet.2015.05.080

[35] Zhao Z., Yang Z., Hu Y., Li J., Fan X.: Multiple functionalization of multi-walled carbon nanotubes with carboxyl and amino groups. Applied Surface Science, 276, 476-481 (2013). https://doi.org/10.1016/j.apsusc.2013.03.119 
[36] Wu C-S.: Antibacterial and static dissipating composites of poly(butylene adipate-co-terephthalate) and multiwalled carbon nanotubes. Carbon, 47, 3091-3098 (2009). https://doi.org/10.1016/j.carbon.2009.07.023

[37] Vega-Castro O., Contreras-Calderon J., León E., Segura A., Arias M., Pérez L., Sobral P. J. A.: Characterization of a polyhydroxyalkanoate obtained from pineapple peel waste using Ralsthonia eutropha. Journal of Biotechnology, 231, 232-238 (2016).

https://doi.org/10.1016/j.jbiotec.2016.06.018

[38] Belekian D., Beyou E., Chaumont P., Cassagnau P., Flat J. J., Quinebèche S., Guillaneuf Y., Gigmes D.: Effect of nitroxyl-based radicals on the melt radical grafting of maleic anhydride onto polyethylene in presence of a peroxide. European Polymer Journal, 66, 342-351 (2015). https://doi.org/10.1016/j.eurpolymj.2015.02.012

[39] Teng C-C., Ma C-C. M., Cheng B-D., Shih Y-F., Chen J-W., Hsiao Y-K.: Mechanical and thermal properties of polylactide-grafted vapor-grown carbon nanofiber/ polylactide nanocomposites. Composites Part A: Applied Science and Manufacturing, 42, 928-934 (2011). https://doi.org/10.1016/j.compositesa.2011.03.021

[40] Grady B. P., Paul A., Peters J. E., Ford W. T.: Glass transition behavior of single-walled carbon nanotube-polystyrene composites. Macromolecules, 42, 6152-6158 (2009). https://doi.org/10.1021/ma900375g

[41] Liao H-T., Wu C-S.: Poly(3-hydroxybutyrate)/multiwalled carbon nanotubes nanocomposites: Preparation and characterizations. Designed Monomers and Polymers, 16, 99-107 (2013).

https://doi.org/10.1080/15685551.2012.705495
[42] Hu Y., Xu P., Gui H., Wang X., Ding Y.: Effect of imidazolium phosphate and multiwalled carbon nanotubes on thermal stability and flame retardancy of polylactide. Composites Part A: Applied Science and Manufacturing, 77, 147-153 (2015). https://doi.org/10.1016/j.compositesa.2015.06.025

[43] Bao S. P., Tjong S. C.: Mechanical behaviors of polypropylene/carbon nanotube nanocomposites: The effects of loading rate and temperature. Materials Science and Engineering: A, 485, 508-516 (2008).

https://doi.org/10.1016/j.msea.2007.08.050

[44] Lin W-Y., Shih Y-F., Jeng R-J., Dai S. A., Lin J-J., Lee C-C.: Nanocomposites with enhanced electrical properties based on biodegradable poly(butylene succinate) and polyetheramine modified carbon nanotube. Journal of the Taiwan Institute of Chemical Engineers, 43, 322328 (2012).

https://doi.org/10.1016/j.jtice.2011.10.009

[45] Grob M. C., Minder E.: Permanent antistatic additives: New developments. Plastics, Additives and Compounding, 1, 20-26 (1999). https://doi.org/10.1016/S1464-391X(99)80074-9

[46] Yadav S. K., Mahapatra S. S., Cho J. W.: Synthesis of mechanically robust antimicrobial nanocomposites by click coupling of hyperbranched polyurethane and carbon nanotubes. Polymer, 53, 2023-2031 (2012). https://doi.org/10.1016/j.polymer.2012.03.010

[47] Allion-Maurer A., Saulou-Bérion C., Briandet R., Zanna S., Lebleu N., Marcus P., Raynaud P., Despax B., Mercier-Bonin M.: Plasma-deposited nanocomposite polymer-silver coating against Escherichia coli and Staphylococcus aureus: Antibacterial properties and ageing. Surface and Coatings Technology, 281, 1-10 (2015). https://doi.org/10.1016/j.surfcoat.2015.09.025 